\title{
Recent experiences with the Telephone helpline service at the central STD clinic, Colombo.
}

\author{
${ }^{1}$ Dr WSC Dileka, ${ }^{2} \operatorname{Dr}$ KYD Perera, ${ }^{3} \operatorname{Dr}$ HMAH Karunaratne, ${ }^{4}$ Dr MPVR Perera, \\ ${ }^{5}$ Dr KACR Wijesekara
}

\begin{abstract}
Introduction: The telephone helplines of the central STD clinic, Colombo provide sexual health information and guidance on STI care and treatment for the general public. However, caller profiles have not been explored or analyzed systematically during the recent past.

Objectives: To describe the caller profiles and the content of the calls received to the telephone helpline.

Methods: Details on all 215 telephone calls received to helpline during April-July, 2019 were recorded using a data extraction sheet after the verbal consent of the client.

Results: Most callers (93\%) were males with the median age of 22 years (range 15-65) and well educated (51\%). The majority were first-time callers (84\%). Reasons for calling included to inquire service delivery points (78\%), HIV or HIV testing (62\%), HIV symptoms (58\%), Pre Exposure Prophylaxis related (11\%), STI symptoms (21\%) and sexual dysfunctions (12\%). Thirty-four (34\%) were due to misconceptions related to sexual health and HIV. Most callers (59\%) discovered the hotline through internet $(n=126)$ while almost $10 \%$ were linked at a lecture and $6.5 \%$ by a peer and the rest as a result of TV programmes or newspaper articles
\end{abstract}

Conclusions: People are using telephone helpline effectively. Therefore, further advertising on helpline through social media and other web sites and expansion of the services to the periphery is recommended. Reasons for less inquiries made by females should be further explored and attended. Timely actions to alleviate misconceptions regarding sexual health and HIV while raising awareness on available services need to be encouraged.

Key words: Telephone helpline, Sexual health, sexually transmitted infections, HIV

Authors: ${ }^{1}$ Dr WSC Dileka (MBBS, Pg Dip M\&E, Pg Dip Ven, MD), Acting Venereologist, Base hospital, Wathupitiwala. ${ }^{2}$ Dr KYD Perera (MBBS, Pg Dip CH, PgHQPS, Pg Dip M\&E, MSc.Med Admin), Registrar in Med Adm.

${ }^{3}$ Dr HMAH Karunaratne (MBBS, PgDip Ven, Pg Dip M\&E, MD), Acting Venereologist, National STD/AIDS Control Programme, Colombo. ${ }^{4}$ Dr MPVR Perera (MBBS, Pg Dip Ven, MD); Acting Venereologist, National STD/AIDS Control Programme, Colombo. ${ }^{5}$ Dr KACR Wijesekara (MBBS, PG Dip in Ven, MD); Acting Venereologist, National STD/AIDS Control Programme, Colombo.

Corresponding author: ${ }^{1}$ Dr WSC Dileka, chamdileka@gmail.com Conflict of interest: None declared

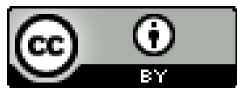

Financial support: none

Originality of the work: The article is original work and has been presented at the 24th annual scientific sessions of Sri Lanka College of Sexual Health and HIV medicine 


\section{Full Article}

\section{Introduction}

Even though Sexuality is an integral part of life, Sri Lanka, as in many other parts of the world, talking about sexuality is a taboo subject and is shrouded in secrecy. Although a substantial proportion of people are suffering with sexual problems, difficulties or dysfunctions they do not seek direct advice from a clinician or specialist.(1)

Unfortunately, despite increasing sexually transmissible infections (STIS), HIV/AIDS, (2) and countless unhealthy reproductive practices, there is still a large unmet demand for adequate Sexual Health (SH) information and services. In some parts of the country, the cultural beliefs still spread misinformation, culminating in various risky practices. It has been found that, knowledge on HIV/AIDS among married girls between 15-24 years in Sri Lanka was low (24\%).(3)

Unlike many countries in the world, Sri Lanka has a well-established national programme for the control of STI and HIV with its branch clinics island wide. The services provided through these clinics conform a wide variety of unmet sexual health needs of the population. However, still there is a significant proportion who are reluctant to attend clinics due to societal stigmas, fears, misconceptions and misinformation.(2) High risk sexual behaviours, such as early sexual debut, premarital sex, multiple partners and bisexual orientation, are also increasingly becoming common among young people,(2) while sex education for the young is limited and also a controversial issue in many countries across the world.(4) Further, a study in Sri Lanka, revealed lack of knowledge among young people aged 17-19 years to result in low self-confidence and psychological distress, especially with regard to masturbation practices and menstruation periods.(6) All of which emphasize the need of contemporary approaches to encourage the sexual health care seeking behavior of the society.

With the intention of increasing accessibility of services to anyone who has a sex related query and to provide services in a non-judgmental manner, an anonymous and free of charge telephone helpline is set-up at the national STD/AIDS control programme (NSACP) main clinic premises since 2017. This is functional on Monday to Saturday from 8.a.m to 4.p.m. The telephone conversations are handled by a trained senior medical officers even though there was no designated medical officer for the task. The helpline objectives are to provide an access to accurate and comprehensible information on $\mathrm{SH}$ issues, provide counselling to empower individuals to make safe and healthy sexual decisions, provide a referral service to appropriate specialty and to increase the number of people who seek care in sexual health clinics and increase uptake of HIV testing.

Telephone counselling differs from face to face counselling in many ways. The calls are received from individuals of all socioeconomic, educational and professional backgrounds. The helpline service is an excellent medium for communication of sexual health and HIV related matters, as it promises confidentiality and anonymity, with alleviation of geographical constraints between the needy and the service provider, at a very low cost.(7)

There were average 10-15 calls received to this telephone helpline per day. However, these calls were not documented even though it is practiced in some telephone helpline services in other countries. Those studies have described, interesting information about SH knowledge, beliefs, practices and health-care seeking behaviour of the people through the data gathered via the helpline (7). However, in Sri Lanka the caller profiles were not documented or assessed with the view of describing their knowledge, beliefs and misconceptions as well as health care seeking behaviour. In addition, it will provide further means to access population which cannot be accessed by regular clinic services. Therefore, this study was carried out with the aim of filling this existing gaps related to telephone helpline and to make recommendations based on the assessment of caller profiles. 


\section{Method}

This was a descriptive cross-sectional study which was carried out at the central clinic of the national STD and AIDS control programme premises during April-July, 2019. Data collection were carried out by trained MD qualified medical officers who attended the calls received by the telephone helpline. All the telephone calls received to the telephone helpline during April-July, 2019 were eligible to the study. All the relevant data were recorded using a data-extraction-sheet. Informed verbal consent was taken from the callers at the end of the conversation, to avoid the bias. Only the data of the callers who gave consent were included in the study and records of any caller refusing to participate were removed. Any personal identifiable information was not documented. All the researchers were trained with a script of guidance on how to handle the call.

The data extraction form was composed of 4 sections. Section A- collected Demographic data of study sample. Section B recorded all the details discussed with the client through telephone conversation. Section C included the sexual history of the client and section $D$ gathered data on the source of information about help line. At the end of the conversation the patients who needed further care were linked to services with the most convenient STD clinic or other services. Such patients who planned to visit an STD clinic, were asked to inform the registration desk that were referred through telephone helpline.

Due to the limited number of period and number of clients are limited to 10-15 per day all the consecutive calls were included in the survey. During the period, details of 215 calls were documented.

Excel data base was prepared using the data extraction forms after translating all the responses to English. The data were analyzed using Microsoft Excel. The quantitative data were analyzed with regards to measures of central tendency and dispersion. Categorical data were analyzed with regards to proportions. Qualitative data were analyzed in the form of thematic analysis. Themes were identified by the frequency of repeating similar responses.

\section{Results}

\section{Sociodemographic characteristics}

Majority $(93 \%, \mathrm{n}=201)$ were males and between $18-25$ age group ( $n=124)$, with the age range of $16-65$ years. Out of 14 females 10 inquired about a sexual health issue of another close person. The Majority (54\%) of the callers were educated up to Advanced Level and above. Six school children have inquired their sexual health related matters. Only $51 \%$ of calls were received from the Western province and other callers were from around the country. Most preferable hours of calling were identified between 8 am to 12 noon according to the timing of calls.

Table 1 - Socio-demographic characteristics of callers

\begin{tabular}{|c|c|c|c|}
\hline \multicolumn{2}{|c|}{ Variables and levels } & \multirow{2}{*}{$\begin{array}{r}\text { Count } \\
201\end{array}$} & \multirow{2}{*}{$\begin{array}{r}\text { Percent } \\
93 \%\end{array}$} \\
\hline Gender & Male & & \\
\hline & Female & 14 & $7 \%$ \\
\hline & Total & 215 & $100 \%$ \\
\hline \multirow{6}{*}{$\begin{array}{l}\text { Age } \\
\text { (Years) }\end{array}$} & $16-25$ & 132 & $61 \%$ \\
\hline & $26-35$ & 41 & $19 \%$ \\
\hline & $36-45$ & 11 & $5 \%$ \\
\hline & $46-55$ & 14 & $7 \%$ \\
\hline & $56-65$ & 17 & $8 \%$ \\
\hline & Total & 215 & $100 \%$ \\
\hline \multirow{6}{*}{$\begin{array}{l}\text { Educatio } \\
\text { n Level }\end{array}$} & grade 8 & 64 & $30 \%$ \\
\hline & $\mathrm{O} / \mathrm{L}$ & 34 & $16 \%$ \\
\hline & $A / L$ & 84 & $39 \%$ \\
\hline & Graduate & 20 & $9 \%$ \\
\hline & Postgraduate & 13 & $6 \%$ \\
\hline & Total & 215 & $100 \%$ \\
\hline \multirow{4}{*}{$\begin{array}{l}\text { Frequen } \\
\text { cy of } \\
\text { calling }\end{array}$} & 1 time & 195 & $91 \%$ \\
\hline & 2 times & 12 & $6 \%$ \\
\hline & $\begin{array}{l}\text { Frequent caller } \\
(>2 \text { times })\end{array}$ & 8 & $4 \%$ \\
\hline & Total & 215 & $100 \%$ \\
\hline \multirow{10}{*}{$\begin{array}{l}\text { Resident } \\
\text { ial } \\
\text { province } \\
\text { of the } \\
\text { caller }\end{array}$} & Western & 110 & $51 \%$ \\
\hline & Southern & 14 & $7 \%$ \\
\hline & North Western & 20 & $9 \%$ \\
\hline & North & 4 & $2 \%$ \\
\hline & East & 0 & $0 \%$ \\
\hline & Sabaragamuwa & 16 & $7 \%$ \\
\hline & Central & 17 & $8 \%$ \\
\hline & Uva & 10 & $5 \%$ \\
\hline & North Central & 24 & $11 \%$ \\
\hline & Total & 215 & $100 \%$ \\
\hline
\end{tabular}


Reasons for contacting the telephone helpline.

The reasons for calling is shown in table 2 .

Table 2- The reason of calling the telephone helpline $(\mathrm{N}=215)$

\begin{tabular}{|l|r|r|}
\hline Category & Count & percent \\
\hline Service delivery points & 167 & $78 \%$ \\
\hline HIV \& testing related & 134 & $62 \%$ \\
\hline Clinic appointments & 17 & $8 \%$ \\
\hline STI & 45 & $21 \%$ \\
\hline Sexual Dysfunctions & 25 & $12 \%$ \\
\hline Misconceptions & 73 & $34 \%$ \\
\hline Others & 11 & $5 \%$ \\
\hline
\end{tabular}

*Categories are not mutually exclusive (multiple answers possible)

Reasons for calling included calls to inquire service delivery points (78\%), inquiries on HIV or HIV testing (62\%), inquiries for HIV symptoms (58\%), PrEP inquiries (11\%), calls to query STI symptoms (21\%) and sexual dysfunctions related inquiries (12\%). \%). Eight percent of the patients inquired on the possibility of making an appointment. Eleven calls $(5 \%)$ were from healthcare workers inquiring about post-exposure prophylaxis (PEP) and patient related matters. Interestingly, $(34 \%, n=73)$ was came up with misconceptions regarding sexual health, HIV and STI transmission. Among them most were related to HIV transmission $(n=22)$ masturbation $(n=24)$ and pre marriage anxiety $(n=18)$. Variety of psychosomatic symptoms caused by myths and misconceptions about masturbation were common such as losing energy, weight loss and guilty feeling which are deep rooted and culturally reinforced.

Table 3 - Distribution of calls according to the HIV related problem of the callers $(\mathrm{N}=134)$

\begin{tabular}{|c|c|c|}
\hline Category & Count & Percent \\
\hline Symptoms of HIV & 75 & $58 \%$ \\
\hline HIV testing & 24 & $17 \%$ \\
\hline $\begin{array}{l}\text { Window period of HIV } \\
\text { testing }\end{array}$ & 56 & $41 \%$ \\
\hline PrEP & 15 & $11 \%$ \\
\hline $\begin{array}{l}\text { Doubts whether they have } \\
\text { HIV }\end{array}$ & 34 & $25 \%$ \\
\hline
\end{tabular}

Details of persons who called inquiring HIV related problem are shown in the table3. Among the callers inquiring about HIV related problems, 58\% ( $\mathrm{N}=75)$ inquired about their symptoms and $25 \%(n=34)$ were in doubt whether they have features of HIV. Among them $17 \%$ were inquired on HIV testing facilities. Interestingly $26 \%$ inquired about exact timing of testing while $11 \%$ inquired about PrEP.

Table 4- Distribution of calls according to the sexual behavior of the caller.

\begin{tabular}{|c|c|c|c|}
\hline \multicolumn{2}{|c|}{ Variables and levels } & \multirow{2}{*}{$\begin{array}{r}\text { Count } \\
60\end{array}$} & \multirow{2}{*}{\begin{tabular}{|r} 
Percent \\
$28 \%$
\end{tabular}} \\
\hline Number of & 1 partner & & \\
\hline partners & 1-5 partners & 120 & $56 \%$ \\
\hline year & $>5$ partners & 35 & $16 \%$ \\
\hline & Total & 215 & $100 \%$ \\
\hline \multirow{3}{*}{$\begin{array}{l}\text { Last sexual } \\
\text { exposure }\end{array}$} & Hetero & 125 & $58 \%$ \\
\hline & Homo & 90 & $42 \%$ \\
\hline & Total & 215 & $100 \%$ \\
\hline \multirow{4}{*}{$\begin{array}{l}\text { Adhere to } \\
\text { safe sexual } \\
\text { practices }\end{array}$} & Condom used & 65 & $30 \%$ \\
\hline & $\begin{array}{l}\text { Condom } \\
\text { ruptured/slipp } \\
\text { ed }\end{array}$ & 10 & $5 \%$ \\
\hline & $\begin{array}{l}\text { Not used } \\
\text { condom }\end{array}$ & 140 & $65 \%$ \\
\hline & Total & 215 & $100 \%$ \\
\hline
\end{tabular}

Sexual behaviours of callers are summarized in table 4. Almost all were having at least one unprotected sexual exposure at some stage of their life while majority were having more than one partner.

Table 5- Source of information regarding the helpline

\begin{tabular}{|l|r|r|}
\hline Category & Count & Percent \\
\hline Internet & 126 & $59 \%$ \\
\hline Peers & 14 & $7 \%$ \\
\hline $\begin{array}{l}\text { Health education outreach } \\
\text { lectures }\end{array}$ & 21 & $10 \%$ \\
\hline $\begin{array}{l}\text { TV programmes/ Newspaper } \\
\text { articles }\end{array}$ & 54 & $25 \%$ \\
\hline Total & 215 & $100 \%$ \\
\hline
\end{tabular}

Table 5 summarizes the source of information about the helpline. Callers had found out about the hotline through internet $(n=126)$, as a link to care services in lectures $(n=21)$, from a peer $(n=14)$ and the rest as a result of TV programmes and Newspaper articles. Internet emerged as the main source of information in 
the study sample which highlights the importance of incorporating information technology in the service provision.

Only about $7 \%$ of the patients turned up as a result of requesting to visit the NSACP in person. However, there may be instances where patients visited STD clinics other than the Colombo clinic or Patients not disclosing about being referred through the helpline.

Majority (80\%) were satisfied about the service provided through telephone helpline. However, this information may not be reliable since the health care worker inquired this information from the caller which can introduce bias. The time which can be allocated for a single call was identified as a limited factor by all the data collectors.

\section{Discussion}

The telephone helpline of NSACP is an effective resource to elicit information and opportunities that otherwise might remain hidden and act as a useful link between healthcare system and the general public. It is interesting that people are using this help line effectively to clarify their issues related to HIV, STI and sexal health. Mostly young educated males are accessing the service. A majority inquired on service delivery points and HIV related information while STI inquiries were made by only one-fifth of callers. A considerable number of callers inquired about pre-exposure prophylaxis and sexual dysfunctions. Nearly one third of the callers came up with misconceptions regarding sexual health and HIV, which highlights the unmet need of sexual health education in the society.

Even though considerable proportion inquired about HIV testing and window period it demonstrates only $7 \%$ turned up at the NSACP. This may be due to lack of record keeping, patients visiting other STD clinics and patients being reluctant to reveal the true mode of referral. In the majority of callers, the source of information regarding helpline was the internet which encourage promotion of sexual health through social media and other web sites.

\section{Conclusions}

The fact that the majority of callers are being young adults, highlights the importance of innovative methods of reaching them to address their sexual health related matters while alleviate misconceptions regarding sexual health and HIV. However, it will be more effective if this helpline can be advertised further through social media and other web sites. Expansion of the helpline to other peripheral STD treatment centers to provide a better service is recommended. Further it is encouraged to appoint a specific trained health care person, to carry out proper counselling and record keeping. Reasons for less inquiries made by females should be further explored with the view of approaching females with unmet sexual health needs. On the other hand, in times of service delivery interruptions, such as in unexpectable emergency situations in the country, it also emphasizes the importance of a telephone helpline in service delivery and it is timely to extend the service to other STD centers as well.

\section{Reference}

1. Newton-Levinson A, Leichliter JS, Chandra-Mouli V. Help and Care Seeking for Sexually Transmitted Infections Among Youth in Low- and Middle-Income Countries. Sex Transm Dis. 2017 Jun;44(6):319-28.

2. Strategic Information Management unit, NSACP. Annual report 2018. Sri Lanka: National STD/AIDS Control Programme, Ministry of Health; 2018.

3. Dept. of Census and Statistics and Health Sector Development Project, Demographic and Health Survey 2016. 2017, MInistry of Health.

4. Vanwesenbeeck I, Westeneng J, Boer T de, Reinders J, Zorge R van. Lessons learned from a decade implementing Comprehensive Sexuality Education in resource poor settings: The World Starts With Me. Sex Educ. 2016 Sep 2;16(5):47186.

5. Sri Lanka National HIV STI Strategic Plan 2018-2022 2017.pdf [Internet]. [cited 2020 May 2]. Available from: https://www. aidsdatahub. org/ sites/default/files/publication/Sri Lanka National HIV STI Strategic Plan 2018-2022-2017.pdf

6. Agampodi SB, Agampodi TC, Ukd P. Adolescents perception of reproductive health services in Sri Lanka. BMC Health Serv Res 2008; 8: 98.

7. Tomlinson JM, Fernandes LC, Wylie KR. An e-mail and telephone helpline for sexual problems results of a 2-year survey of men's sexual concerns. Int J Clin Pract. 2011;65(10):1085-91. 